\title{
Téoros
}

Revue de recherche en tourisme

\section{Des Gagniers, Jean (1994), Charlevoix pays enchanté, Presses de} l’Université Laval

\section{Claude Moulin}

Volume 17, numéro 1, printemps 1998

Le tourisme dans un Pays à part : Charlevoix

URI : https://id.erudit.org/iderudit/1072381ar

DOI : https://doi.org/10.7202/1072381ar

Aller au sommaire du numéro

Éditeur(s)

Université du Québec à Montréal

ISSN

0712-8657 (imprimé)

1923-2705 (numérique)

Découvrir la revue

Citer ce compte rendu

Moulin, C. (1998). Compte rendu de [Des Gagniers, Jean (1994), Charlevoix pays enchanté, Presses de l'Université Laval]. Téoros, 17(1), 59-60.

https://doi.org/10.7202/1072381ar

Ce document est protégé par la loi sur le droit d'auteur. L'utilisation des services d'Érudit (y compris la reproduction) est assujettie à sa politique d'utilisation que vous pouvez consulter en ligne.

https://apropos.erudit.org/fr/usagers/politique-dutilisation/
Cet article est diffusé et préservé par Érudit.

Érudit est un consortium interuniversitaire sans but lucratif composé de l’Université de Montréal, l'Université Laval et l'Université du Québec à Montréal. Il a pour mission la promotion et la valorisation de la recherche. https://www.erudit.org/fr/ 


\section{Charlevoix pays enchanté}

Claude Moulin, professeure Université d'Ottawa

Des Gagniers, Jean (1994), Charlevoix pays enchante, Presses de l'Université Laval.

\section{INTRODUCTION}

L'auteur Des Gagniers sous le charme de cette région, de ce pays unique qu'il dit enchanté. nous retrace l' histoire complète et communique la richesse de ces paysages par le dialogue qu'il entretient entre les éléments, la côte et le fleuve. L'histoire du peuplement, des pionniers qui, par leur ténacité et leur dynamisme, ont fait de Charlevoix aun pays enchanté ou, com= me le dira Savard, le comté métaphysique de la Province de Québec.

Ce pays a une âme, des paysages de grande beauté et une qualité de valeurs traditionnelles. Il est d'ailleurs reconnu par I'UNESCO comme une région de la biosphère (MAB). $\mathrm{Ce}$ pays quoique enchanté n'est pas imaginaire, i] est réel.

Le livre s'organise en plusieurs parties. La première partie du livre traite de l'histoire géologique pour, plus tard, en comprendre les paysages, leur beauté et leur richesse, La topographie de Charlevoix a été transformée par un météorite énorme, il y a 350 millions d'années. L'auteur détaille et tente de nous présenter les événements importants tels que la glaciation et son impact sur le paysage actuel. II s'applique aussi à nous émouvoir en décrivant admirablement l'environnement de Charlevoix et notamment le fleuve et ses rivages. Le Saint-Laurent a été utilisé par les premiers Européens pour pénétrer au coeur des terres. Le climat est étudié, climat rude mais livrant de merveilleuses beautés comme la forêt, avec ses multiples espèces.

La seconde partie s'intéresse aux premiers occupants et aux découvreurs. Nous y apprenons que les Amérindiens, et particulièrement les Montagnais se réunissaient à Tadoussac pour des échanges commerciaux. Ils pratiquaient la chasse et lá cueillette. Des Gagniers, par sa narration élégante et riche nous entraîne dans leur univers nous permettant ainsi de découvrir les traditions et la vie quotidienne. Les passages traitant des croyances et des rites sont habilement écrits et passionnants.

Le XVI et XVIIr siècles sont étudiés. On relate le parcours et quelques péripéties de Jacques Cartier qui mouillera à Tadoussac en 1535. Dans les pages qui suivront, Des Gagniers dépeint les réussites et les difficultés que rencontrent les explorateurs pour remonter le fleuve. Les Basques sont đéjà là et pêchent la morue et la baleine. Ils possèdent des installations. Des bagarres se déclenchent entre Champlain et les Basques.

La section suivante intitulée A Au Temps des Seigneurs* traite du développement de la Nouvelle-France et de son peuplement. La région, entre 1664 et 1760, verra sur les deux rives du Saint-Laurent la création de près de 300 seigneuries.
L'auteur présente différentes seigneuries comme celles de l'île aux Coudres, des Éboulements, etc. et fait état des conflits sévères qui font rage entre la France et l'Angleterre.

A partir de la section IV l'auteur concentre son travail de recherche sur le XIX ${ }^{c}$ siècle et la façon dont la région sera occupée, transformée, développée et habitée. Après les affrontements, une fois les seineurs écossais installés à la Malbaie, la vie reprend son cours. Les familles nombreuses travaillent la terre et de nouveaux rangs sont ouverts. L'expansion est décrite en détail et la lecture en est passionnante tellement le style est facilc à lire et nous plonge dans un univers harmonieux. Dejà. au début des années 1900, le tourisme prendra forme grâce aux bateaux à vapeur à grandes roues qui seront remplacés par des navires-palaces.

L'émigration vers le Saguenay crécra une véritable hémorragie ce qui occasionnera des difficultés. Au chapitre V l'auteur décrit les habitants, la vie de ces paysans qui possèdent une saison agricole relativement courte. Semailles, labourage, récolte tout s'enchaîne rapidement. Les hommes exploitent la forêt. Ainsi sont décrites les activités nombreuses et variées. L'auteur nous présente aussi les gens de mer et les constructeurs de goélette.

Au chapitre VI ce sont les villages et leurs habitants qui sont décrits. Les détails sont nombreux, précisent le type d'architecture, le design des fermes et des maisons de ferme traditionnelles, les étoffes utilisées, la fabrication de l'artisanat, des garde-robes, et le style de vie. Là, on se rend compte que l'hiver, loin d'être une 


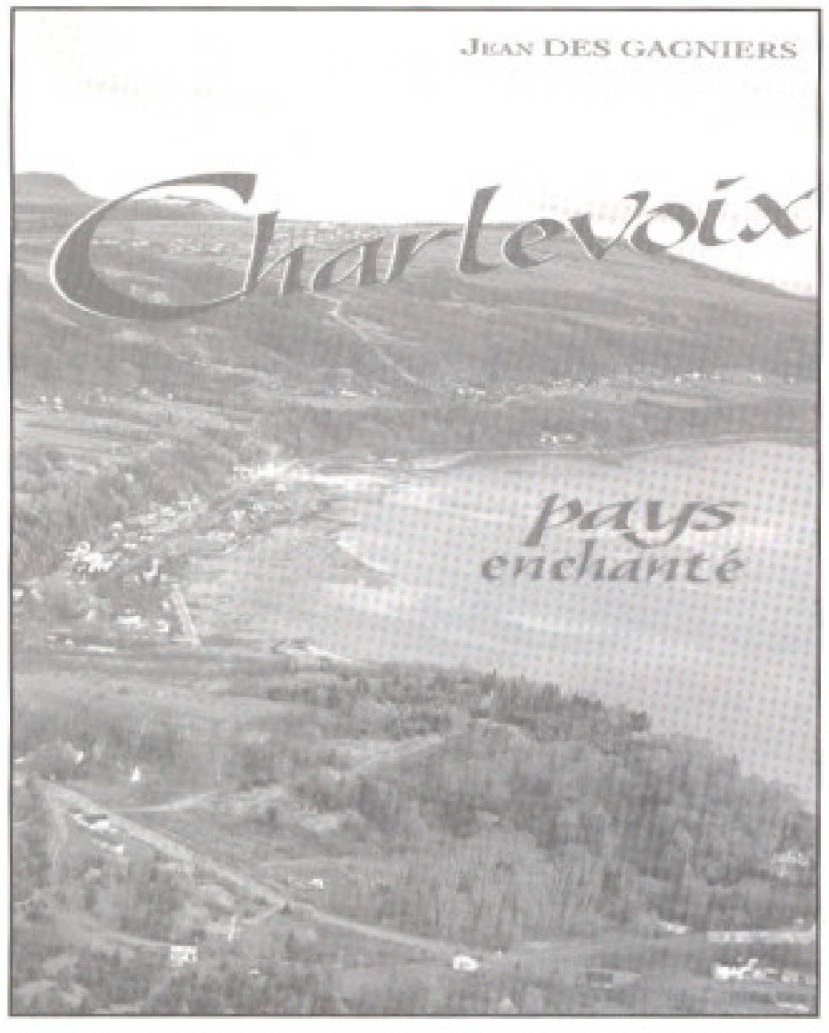

connaissance de son histoire et de son évolution. $\mathrm{C}^{*}$ est le propos que nous tient l'auteur.

Le livre est fascinant, émouvant, nous instruit mais nous force à l'émotion qui nous touche profondément et nous transforme. Un espoir naît à la page 439 , celui de conserver et protéger ce lieu magnifique, cet environnement alliant l'harmonie de la nature et de la culture.

\section{CONCLUSION}

Ce livre est passionnant pour qui apprécie géographie, histoire, ethnologie et vibre aux descriptions admirables de la région et de ses moeurs. Cependant il s'agit d'un volume de 500

saison triste, donne l'occasion de fêtes et de réjouissances nombreuses. Les fêtes entrainent des repas aux mets savoureux, de la musique et de la danse.

L'hiver au Canada est la saison où tout le monde s'amuse. Dès qu"arrivent les jours froids et clairs, chacun met de côté tout souci d'affaires et se consacre au plaisirm

Dans la partie suivante intitulée charlevoix redécouvertw, l'auteur nous invite à remonter dans le temps pour réaliser que Charlevoix était une région touristique appréciée. Elle sera une région très prisée, élégante où les Américains viendront et transformeront certaines habitudes. Des villas somptueuses, des jardins d'agrément seront développés et de grands hôtels accueilleront de riches touristes.

Dans le chapitre suivant, l'auteur présente un pays qui traduit une exaltation devant un paysage pur, à part, empreint de beauté naturelle et riche d'un patrimoine culturel. Mais depuis un demi-sičcle cette région a dû s'adapter et Des Gagniers nous signale que ce patrimoine est en grand danger. Car il est nécessaire de connaître profondément son patrimoine pour aimer le conserver et lui permettre d'affronter le changement. Préservation, mise en valeur d'un lieu magique demandent une pages, édité par les Presses de l'Université Laval, sur un papier glacé de grande qualité. Le livre est lourd et encombrant. II n'incite pas à la lecture celui qui est pressé ou lit dans le bus ou le métro. Il est recommandé a ceux ou celles qui sont impliqués dans le développement touristique et la conservation du patrimoine puisqu'il dévoile le sens et l'esprit de ce lieu sur lequel doivent s'appuyer les activités et attractions touristiques. Quelques remarques également doivent nous faire réfléchir sur le rythme accéléré des chan= gements et la perte éventuelle des valeurs et qualités qui font de Charlevoix une contrée exceptionnelle, un pays unique et wenchantéw.

Quelques publications récentes témoignent de l'intérêt croissant dans le monde pour l'étude des relations entre tourisme et culture:

UNESCO, (1997), Culture, tourisme, développement: les enieux du XXF siècle. Collection Culture et développement, UNESCO/AIEST/Annals of Tourism Research.

Le document est le compte-rendu d'un seminaire de réflexion. sous la forme d'une table ronde qui aborde les tendances du tourisme. L'UNESCO s"intéresse au tourisme comme partenaire dans le cadre des interactions entre la culture et le développement. La réflexion porte sur le tourisme comme champ privilégié pour un dialogue interculturel et le maintien des identités culturelles. Ainsi le tourisme doit faciliter, par une gestion et un développement appropriés, la préservation des sites naturels et culturels. Le livre prồne la formation d'une étique et le développement de politiques.

Tourism and Herifage management, Wiendu Nuryanti éditeure, published by Gadjah Mada University Press in association with the International Centre for Culture and Tourism (ICCT). ISBN 979. 420-4277. Proceedings of the 1996 International Conference on Tourism and Heritage Management, Indonesia.

(1996),Culural Tourism in Europe, edited by Greg Richards, CAB International, UK.

Boniface, Priscilla (1995), Managing Quality Cultural Tourism, Routledge, $124 \mathrm{p}$.

Soulignons enfin la parution d'un ouvrage collectif qui permet d'approfondir tous les aspects des rapports entre culture et tourisme autant sur le plan thérique qu'au niveau des interventions:

Lanfant, Marie-Françoise, John B. Alloock et Edward M. Bruner (1995), /nternational Tourism. Identity and Change, London, Sage Publications Ltd. Sage Studies in International Sociology, no 47 .

Ce livre est tout autre chose qu' un assemblage de chapitres par divers auteurs. Sous l'impulsion de l'Unité de recherche et d'études en sociologie du tourisme international (URESTI) de France se crée, en 1990, un groupe de recherche officiellement reconnu par l'Association internationale de sociologie (AIS) pour l'étude du tourisme comme fait international. L'idée du livre est née à ce moment-là et plusicurs chercheurs ont amorcé leur contribution. Le groupe est devenu un comité permanent de recherche de l'AIS en 1994 lors de son congrès mondial à Bielefeld en Allemagne. Le présent livre rend compte alor's des travaux d'une équipe internationale sur plus de six ans.

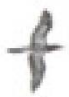

